\title{
Recent developments in the management of dry age-related macular degeneration
}

\author{
This article was published in the following Dove Press journal: \\ Clinical Ophthalmology \\ I April 2015 \\ Number of times this article has been viewed
}

\author{
Elisa Buschini \\ Antonio M Fea \\ Carlo A Lavia \\ Marco Nassisi \\ Giulia Pignata \\ Marta Zola \\ Federico M Grignolo \\ Ospedale Oftalmico, Ophthalmic \\ Section, Department of Clinical \\ Pathophysiology, University of Turin, \\ Turin, Italy
}

\begin{abstract}
Dry age-related macular degeneration (AMD), also called geographic atrophy, is characterized by the atrophy of outer retinal layers and retinal pigment epithelium (RPE) cells. Dry AMD accounts for $80 \%$ of all intermediate and advanced forms of the disease. Although vision loss is mainly due to the neovascular form (75\%), dry AMD remains a challenge for ophthalmologists because of the lack of effective therapies. Actual management consists of lifestyle modification, vitamin supplements, and supportive measures in the advanced stages. The Age-Related Eye Disease Study demonstrated a statistically significant protective effect of dietary supplementation of antioxidants (vitamin C, vitamin E, beta-carotene, zinc, and copper) on dry AMD progression rate. It was also stated that the consumption of omega-3 polyunsaturated fatty acids, such as docosahexaenoic acid and eicosapentaenoic acid, has protective effects. Other antioxidants, vitamins, and minerals (such as crocetin, curcumin, and vitamins B9, B12, and B6) are under evaluation, but the results are still uncertain. New strategies aim to 1) reduce or block drusen formation, 2) reduce or eliminate inflammation, 3 ) lower the accumulation of toxic by-products from the visual cycle, 4) reduce or eliminate retinal oxidative stress, 5) improve choroidal perfusion, 6) replace/repair or regenerate lost RPE cells and photoreceptors with stem cell therapy, and 7) develop a target gene therapy.
\end{abstract}

Keywords: dry AMD, geographic atrophy, new AMD therapy

\section{Introduction}

Age-related macular degeneration (AMD) is a complex and widespread disease that represents a public health problem and a significant challenge for current economic models. The general consensus states that as the population grows and ages, the incidence of the disease will increase as well. Major breakthroughs have been made in the past decades in treating the wet form of AMD and near-term prognosis has improved significantly. Despite every effort, AMD therapy is still not able to prevent or cure this pathology. While preventive genetic screening and counseling are under supervision and may be important parts of preventive medicine, there is a growing need for new treatment options for AMD. In this review, we focus on dry AMD. It accounts for $80 \%$ of all intermediate and advanced forms of the disease. Although vision loss is mainly due to the wet form (75\%), dry AMD remains a challenge for ophthalmologists because of the lack of effective therapies. Actual management of this form is only based on lifestyle modification, vitamin supplements, and supportive measures in the advanced stages.

This article reviews the epidemiological and pathological features, as well as current and potential treatment approaches, of dry AMD.
Correspondence: Elisa Buschini Ospedale Oftalmico, Department of Clinical Pathophysiology, University of Turin, Via Juvarra 19, 10I 22 Turin, Italy

Tel +39 0II 566602 I

Email buschini.elisa@gmail.com 


\section{Epidemiology, etiology, natural history, and prognosis of dry AMD Epidemiology}

AMD is a disorder of the central part of the retina - maculacausing progressive impairment of central vision.

It is considered the leading cause of visual disability and blindness in people over 60 years of age in many Western countries, with severe vision loss occurring in approximately $10 \%-15 \%$ of people with AMD. Allikmets et $\mathrm{al}^{1}$ found that AMD affects at least eleven million people in the USA and 1.2 million people are legally blind as a result of the disease.

Dry AMD, also called geographic atrophy (GA), is characterized by outer retinal and retinal pigment epithelium (RPE) atrophy and accounts for $80 \%$ of all intermediate and advanced forms of the disease. Wet AMD - neovascular, exudative - is caused by choroidal neovascularization growth under the RPE and the retina, exudative hemorrhages and disciform scarring. Vision loss is mainly due to neovascular AMD (75\%) rather than dry AMD (25\%). ${ }^{2}$ The 5-year incidence of advanced AMD, as reported in one of the most important population-based studies - the Beaver Dam Eye Study - appears to be $0.9 \%$, with neovascular AMD affecting $0.6 \%$ of eyes among the general population and dry AMD developing in $0.3 \%$ of cases. Age seems to be the most important risk factor. The prevalence of AMD is approximately $0 \%$ at 50 years, then rises to $2 \%$ at 70 years and to $6 \%$ by the age of 80 years, as stated by Zarbin. ${ }^{3}$ This part of the population is expected to grow within the next decade, and by 2020 , nearly $50 \%$ of the population in the Western world will have AMD. ${ }^{4}$ Early AMD is usually associated with vision impairment, while late-AMD patients have more severe or even complete vision loss.

\section{Etiology}

Apart from age, MD is a complex multifactorial disease, wherein individual genetic susceptibilities - together with environmental factors and metabolic conditions - contribute to the clinical manifestations of the disorder. Smoking is the second most significant risk factor, especially for dry AMD (odds ratio [OR]: 4.5), suggesting a chronic reduction in oxygen supply due to a reduction of blood and tissue oxygen partial pressure (pO2), along with a tendency to ischemic injury. ${ }^{5}$

Clemons et $\mathrm{l}^{6}{ }^{2}$ reported in the Age-Related Eye Disease Study (AREDS, 2005) that the prevalence of AMD is higher in white than in nonwhite people. Contrasting results regarding other risk factors, such as sex or chronic light exposure, have been reported over the years. ${ }^{7-9}$
The hallmark of AMD is the presence of drusen. Drusen are classified as basal linear deposits (BlinD), basal laminar deposits (BlamD), and drusen. ${ }^{10-12}$ They consist of debris accumulated between RPE cells and Bruch's membrane. BlamD and BlinD are very small and can be observed only histologically, by light or electron microscopy. Drusen, instead, are easily seen during a fundus oculi slit-lamp examination. They are bigger, round shaped, and yellowish. Two different drusen types can be observed. Hard drusen, smaller and with clear margins, may be present both in normal aging eyes and in AMD eyes. ${ }^{13}$ In some diseases, such as MDs, long-standing retinal detachment, choroidal nevi, or others, we can find some punctuate deposits that look like hard drusen. Histologically, they share some but not all components with drusen, probably accounting for a different etiopathogenesis. ${ }^{14}$ Although hard drusen can be found in $95 \%$ of the aged population, they are more common in dry AMD, and when associated with retinal pigment alterations and/or soft drusen, the risk of progression is increased. ${ }^{2,5,15}$ Soft drusen are bigger and with indistinct margins. They represent a major risk factor for AMD evolution to advanced stages, both neovascularization and GA. ${ }^{16}$ Most of drusen components are released by the RPE, the neural retina, the choroidal cells, and extraocular sources and all contribute to drusen formation. ${ }^{17-19}$ The origin of drusen is not fully understood, though several hypotheses coexist: the question whether they are derived from the RPE or the choroidal vasculature still remains unanswered. Currently, evidence suggests that both structures contribute to its formation. ${ }^{5} \mathrm{RPE}$ dysfunction and failure of phagocytosis result in debris accumulation in the extracellular space. Alterations of choroidal permeability lead to the same accumulation.

Epidemiological studies suggest that oxidative stress is associated with both the incidence and the progression of AMD. In fact, even though oxidative stress is one of the physiological changes that presents with aging, it is an important cause of retinal damage progression in AMD, as proved in the AREDS, wherein antioxidant supplementations were able to prevent the progression of intermediate and late forms of the disease. ${ }^{5,6}$

Growing evidence suggests that AMD is downstream of a chronic inflammatory condition wherein activation of the immune system plays an important role. Metabolic products accumulate in the extracellular space between Bruch's membrane and the RPE, activating the complement system with a significant increase in oxidative stress, similar to what happens in atherosclerosis or Alzheimer's disease (AD). A variety of drusen components have been recognized: 
proteins (major histocompatibility complex-II, $\beta$-amyloid, apolipoproteins A and E, cytokines, and fibronectin), phospholipids, lipofuscin, advanced glycation end products, and acute-phase proteins that can activate the complement system in response to infections (Chlamydia pneumoniae). ${ }^{20,21} \mathrm{An}$ important regulatory complement protein is complement factor $\mathrm{H}(\mathrm{CFH})$, a major inhibitor of the alternative complement cascade that prevents the complement components from excessive activation to different stimuli; $\mathrm{CFH}$ is synthesized by RPE cells.

Recent studies have demonstrated that a certain polymorphism of a gene in chromosome 1 that encodes $\mathrm{CFH}$ would increase the risk of AMD. This higher susceptibility is observed when a tyrosine amino acid 402 is substituted by a histidine and such a variant may explain up to $50 \%$ of AMD cases. ${ }^{15,20}$

Genetic variants of $C F H$ are associated with a higher risk of AMD. A heterozygous mutation confers a two- to four-fold increased risk, whereas a homozygous mutation augments it to five- to seven-fold.

Epidemiological studies suggest that oxidative stress is able to increase both the incidence and the progression of AMD.

Furthermore, antioxidant supplementations were able to prevent the progression of intermediate and late forms of the disease. ${ }^{5,6}$

\section{Natural history and prognosis}

Nonexudative AMD has a better prognosis compared to wet AMD. ${ }^{22} \mathrm{GA}$ tends to enlarge over time at variable rates to cover the entire macula, typically sparing the foveal zone until the late stages of the disease. The effect of GA on visual acuity (VA) deterioration is crucial; in fact, atrophy spreads at a median rate of $1.72 \mathrm{~mm}^{2}$ per year and it usually takes a number of years from the onset of GA to cause consistent visual loss..$^{23,24}$ The rate of significant visual loss (three or more lines) is reported to be $8 \%$ per year. ${ }^{25}$ The histopathological analysis of dry AMD shows an alteration of the blood-retinal barrier. RPE cellular components show postmitotic damage, with consequent epithelium involution, photoreceptor loss, atrophy of outer retinal layers, and choroidal degeneration. RPE reacts to this loss of cells with pigment clumps around the area of atrophy, typically hyperfluorescent. ${ }^{22,26}$ Areas of increased autofluorescence are constituted of lipofuscin accumulation within the damaged RPE. ${ }^{23}$ Their tendency to enlarge is now considered a prognostic factor for the progression of atrophy and absolute scotoma, therefore for visual loss.

\section{Summary of current management strategies}

Dry AMD management consists of lifestyle modification, vitamin supplements, and supportive measures in advanced stages.

Together with the reduction of body mass index and avoidance of heavy alcohol consumption, lifestyle modifications such as physical activity and quitting smoking are also recommended.

\section{Smoking}

With its ability to increase the oxidative stress and to depress the natural antioxidant system, smoking is significantly associated with increased risk of development and progression of AMD (Early AMD, GA, and choroidal neovascularization).

It is known that smoking may slow down choroidal blood flow, promoting ischemia, hypoxia, and microinfarctions, resulting in a reduction of macular pigments and damage of the RPE.

According to a recent review, there is a dose-effect relationship between the number of years smoking/pack-years smoked and the risk of developing AMD. ${ }^{27}$

\section{Physical activity}

Even though there is no evidence about interactions between active lifestyle and the development of the disease, it is known that physical activity reduces both systemic inflammation and endothelial dysfunction, both of which contribute to AMD pathogenesis.

\section{Alcohol consumption}

Although alcohol consumption could hypothetically be both harmful and protective for AMD Chong et $\mathrm{al}^{28}$ in a systematic review and meta-analysis found an increased risk for early AMD in heavy alcohol consumers (OR: 1.47; 95\% confidence interval, 1.10-1.95). The association between late AMD and heavy alcohol consumption varied in the four analyzed studies, nonetheless in three of them the correlation was positive. The review could not precisely access the role of moderate alcohol consumption on early AMD.

\section{Obesity}

The Atherosclerosis Risk in Communities Study states that middle-aged people with a waist-hip ratio reduction over time were less likely to develop AMD, particularly those who were initially obese. ${ }^{29}$

\section{Diet}

The 10-year incidence of AMD in The Blue Mountain Eye Study and the Alienor Study confirmed that there is a 
decreased risk for AMD in patients with high intake of longchain omega-3 polyunsaturated fatty acids. ${ }^{30}$

Dietary supplementation has been thoroughly investigated by AREDS 1 and 2 and their results will be discussed in the next section.

\section{Supportive measures}

Low-vision rehabilitation is the best option when medical or surgical treatments are unsuccessful or contraindicated. Typical supportive measures include assessment of residual functions and functional vision, identification of preferred retinal loci and training in their active use, prescription and training in the use of low-vision aids, training and educational programs (orientation and mobility), and assistance with daily activities. A systematic review underlines the fact that in the absence of adequate clinical trials, it is impossible to form stronger conclusions regarding the most effective low-vision interventions for individuals with AMD. ${ }^{31}$ Some authors state that augmented low-vision rehabilitation programs are as effective in improving activities of daily living or quality of life as conventional in-clinic rehabilitation programs. $^{32}$

\section{Review of recent developments in dry AMD management}

Regarding dietary supplementation, the two most important studies are the AREDS and the AREDS 2. ${ }^{33,34}$

In the AREDS, the following different antioxidants were administered: vitamin C (500 mg), vitamin E (400 international units [IU]), beta-carotene (15 mg), zinc (80 mg), and copper (2 mg).

\section{Antioxidants}

As the retina is particularly susceptible to oxidative stress, the use of antioxidants may prevent its damage due to reactive oxygen species. The latter play a role in modulating the nuclear factor erythroid 2-related factor 2, involved in the regulation of expression of genes encoding antioxidant proteins. ${ }^{35}$

\section{Zinc}

The development of the disease seems to be influenced by a dysregulation and excessive activation of the complement cascade, leading to accumulation of sub-RPE deposits.

Klevering ${ }^{36}$ in a recent study highlighted that daily zinc supplements for 3 months during AMD could lower the excessive systemic complement activation. However, the benefit of zinc is still debated and a recent meta-analysis confirmed that available data about its role in prevention of AMD are inconclusive. ${ }^{37}$

\section{Copper}

This essential element was evaluated in the AREDS, but its role as a protective agent remains uncertain. In order to avoid a copper deficiency anemia due to zinc intake, this essential trace element, a scavenger of free radicals, has been added in the AREDS. Anyway, its role in AMD protection is still uncertain. ${ }^{38}$

In AREDS, there was a statistically significant reduction in odds for the development of advanced AMD with the use of antioxidants (vitamin C, vitamin E, and betacarotene,) plus zinc and copper. In particular, this reduction was more significant in eyes with extensive intermediate drusen, GA not involving the center of the macula, or at least one large drusen (AREDS category 3) and in people with advanced AMD or VA less than 20/32 in one eye (AREDS category 4$){ }^{33}$

A systematic review and meta-analysis by Chong et $\mathrm{al}^{39}$ suggested that vitamin A, vitamin $\mathrm{C}$, vitamin $\mathrm{E}$, zinc, lutein, zeaxanthin, alpha- and beta-carotene, beta-cryptoxanthin, and lycopene had little or no effect in the primary prevention of early AMD. In a systematic review in 2008, the same authors reported that the consumption of omega-3 polyunsaturated fatty acids, such as docosahexaenoic acid (DHA) and eicosapentaenoic acid (EPA), show protective effects against the progression of AMD. ${ }^{40}$

The randomized controlled trial AREDS 2, published in 2013, investigated the risk of progression from early to advanced AMD.

Three different formulations were evaluated: one without beta-carotene (due to an increased risk of lung cancer in smokers and former smokers), another one with a lower dose of zinc ( $25 \mathrm{mg}$ ), and the third one with both these conditions. Lower dose of zinc was chosen because of the risk of gastrointestinal and genitourinary diseases that zinc itself can induce and because its absorption has been found to be the same even with lower doses. ${ }^{34}$ The results showed that the addition of lutein + zeaxanthin, DHA + EPA, or both to the AREDS formulation had no positive effect on the progression to advanced AMD.

The difference between low-dose versus high-dose zinc was not statistically significant, but lutein + zeaxanthin may be a useful carotenoid substitute in the AREDS formulation in smokers and former smokers (Table 1). ${ }^{34}$

Recent studies discuss the possible positive effects of other antioxidants, vitamins, and minerals (Table 2). 


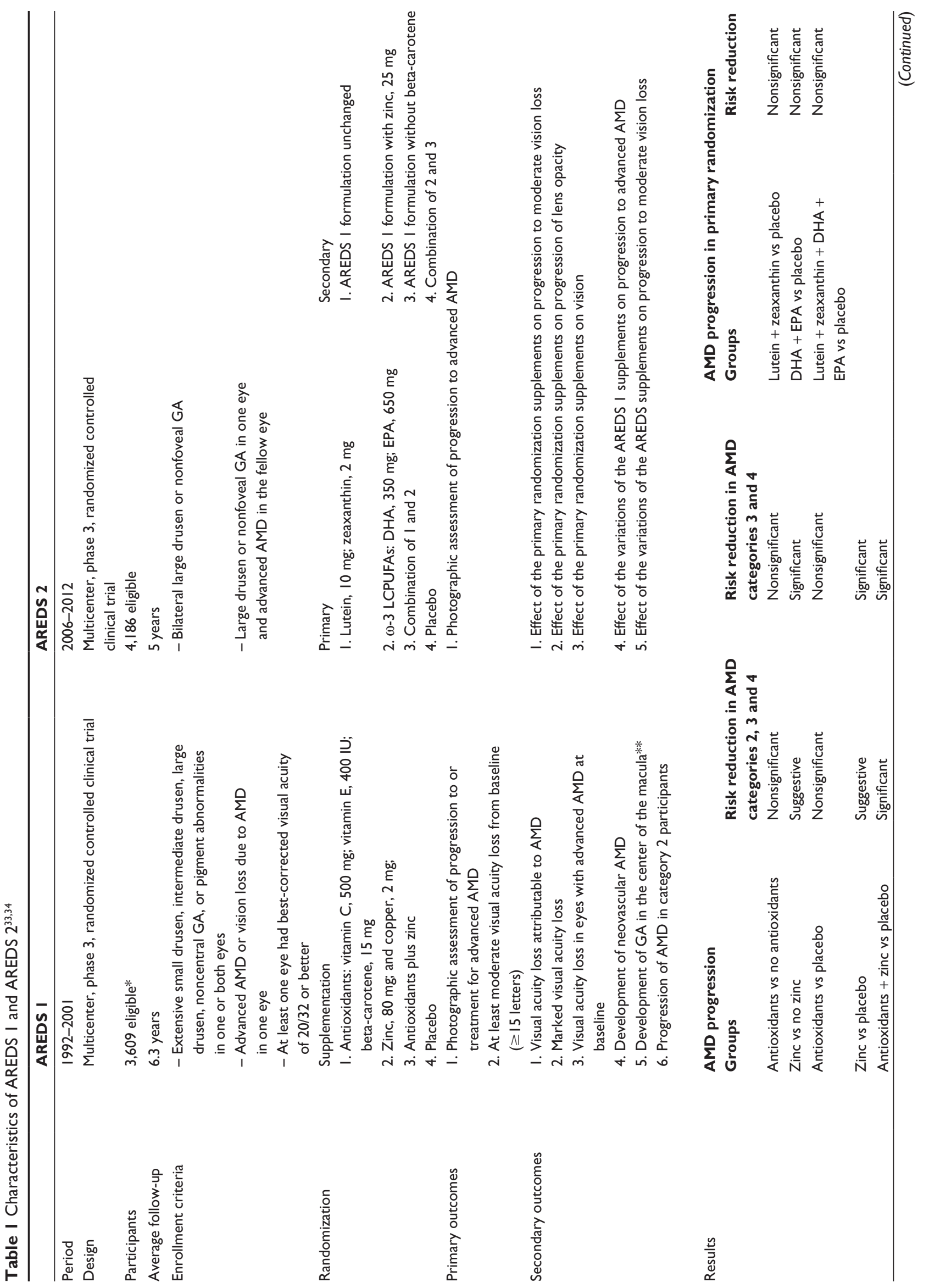




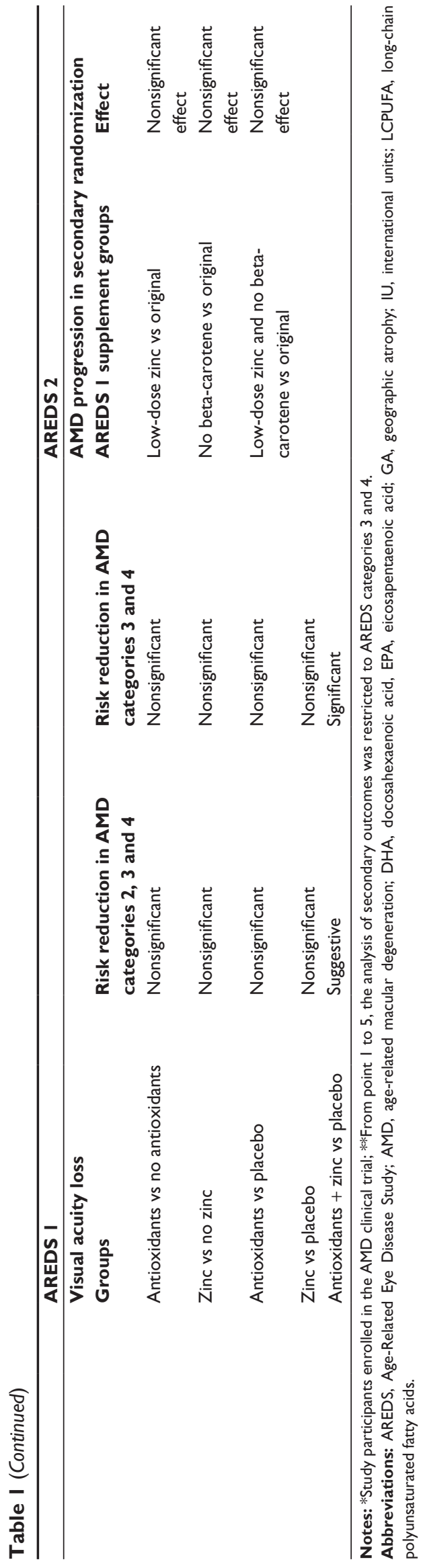

\section{Crocetin}

It is a natural carotenoid dicarboxylic acid, found in saffron, which seems to inhibit caspase activity, reduce the oxidative stress, and protect the retinal tissue from exposure to damaging light in experimental models. ${ }^{41}$ Beyond its antioxidative power, evidence shows that short-term saffron supplementation improves retinal flicker sensitivity in early AMD. ${ }^{42}$

\section{Curcumin}

It can reduce lipid peroxidation and formation of reactive oxygen species. ${ }^{43}$ Its effect on RPE was demonstrated in invitro models only. In a recent article, Chang et $\mathrm{a} l^{44}$ used RPElike cells derived from pluripotent stem cells from patients with dry AMD. Pretreatment with curcumin had a cytoprotective effect against the oxidative stress of $\mathrm{H}_{2} \mathrm{O}_{2}$ through the reduction of $\mathrm{H}_{2} \mathrm{O}_{2}$-induced cell death and reduced reactive oxygen species levels. Furthermore, curcumin modulated the expression of many oxidative stress-regulating genes, such as platelet-derived growth factor, vascular endothelial growth factor $(V E G F)$, heme oxygenase 1, and others. ${ }^{44}$

\section{Vitamins $\mathrm{B} 9, \mathrm{BI}$, and $\mathrm{B} 6$}

These are currently under study in the prevention of AMD but their roles are still uncertain. Beyond their antioxidative powers, they can decrease the serum homocysteine level, reducing the risk of vascular diseases.

Christen et $\mathrm{al}^{45}$ in a recent randomized trial, stated that participants who took daily supplements of folic acid (vitamin B9), pyridoxine (vitamin B6), and cyanocobalamin (vitamin B12) had a decreased risk of AMD.

The richest sources of resveratrol (3,4,5-trihydroxystilbene) are grape skin and seeds, having well known antiaging, anticancer, and cardioprotective properties. In in vitro models of RPE cells, these effects seem to be present through the inhibition of mitogen-activated protein kinase/extracellular signalregulated protein kinase and the VEGF expression. ${ }^{46,47}$

\section{Key concepts of dry AMD}

- Reducing risk factors and providing lifestyle modifications are management strategies that can prevent development and progression of the disease.

- To date, antioxidant supplementation together with intake of some essential elements did not prove effective in primary prevention of AMD.

- In two randomized controlled trials, the use of antioxidants plus zinc and copper was able to reduce the risk of progression to advanced AMD (in AREDS) and the antioxidant carotenoid could be replaced by lutein and zeaxanthin in smokers and former smokers (in AREDS 2). 
Table 2 New antioxidants in dry AMD therapy

\begin{tabular}{|c|c|c|}
\hline Nutrients and elements & Effect & Efficacy \\
\hline \multirow[t]{4}{*}{ Crocetin } & Reduces apoptosis & Animal models ${ }^{41}$ \\
\hline & Increases oxygen diffusion through plasma & Humans (uncertain) ${ }^{42}$ \\
\hline & Reduces lipid peroxidation & \\
\hline & Upregulates trophic factors & \\
\hline \multirow[t]{4}{*}{ Curcumin } & Reduces lipid peroxidation and formation & In vitro models ${ }^{43,44}$ \\
\hline & of reactive oxygen species, modulating the & \\
\hline & expression of many oxidative stress-regulating & \\
\hline & genes, such as PDGF, VEGF, $\mathrm{HOI}$, and others & \\
\hline \multirow[t]{2}{*}{ Resveratrol } & Modulates cell proliferation, apopotosis, & In vitro models ${ }^{46,47}$ \\
\hline & and angiogenesis & \\
\hline Vitamins $\mathrm{B} 9, \mathrm{BI}$, and $\mathrm{B} 6$ & Decrease serum homocysteine level & Humans (uncertain) ${ }^{45}$ \\
\hline
\end{tabular}

Abbreviations: AMD, age-related macular degeneration; PDGF, platelet-derived growth factor; VEGF, vascular endothelial growth factor; HOI, heme oxygenase I.

- New therapeutic approaches target drusen formation, inflammation, oxidative stress, accumulation of toxic by-products, choroidal perfusion, RPE cells, and photoreceptors.

- Future developments in genetics could clarify individual susceptibilities and new targeted therapies.

\section{Future research and directions}

To date, the only therapy available for early AMD and GA is daily intake of antioxidant formulations.

New knowledge in AMD molecular pathogenesis can help us to identify possible therapeutic targets to reduce/stop the stimuli of continuous damage or even to replace, repair, or regenerate the damaged cells.

New strategies are based on the following:

1. Reduce or block drusen formation.

2. Reduce or eliminate inflammation.

3. Lower the accumulation of toxic by-products from visual cycle.

4. Reduce or eliminate retinal oxidative stress.

5. Improve choroidal perfusion.

6. Replace, repair, or regenerate lost RPE cells and photoreceptors.

7. Gene therapy.

\section{Reduce or block drusen formation}

Drusen, both hard and soft, are easily seen during a fundus oculi slit-lamp examination. Almost no cases of AMD exist without prior drusen formation, and the rate of progression correlates with the number and size of drusen. Moreover, GA progression is correlated to drusen regression. ${ }^{48,49}$ Whether they represent a cause or a consequence of the disease is still unclear. New theories postulate that drusen could be an adaptive process, to confine elements potentially detrimental to the retina. ${ }^{50}$ How drusen are formed is not still clear: probably there is a dysregulation of the pathways responsible for proteins and cellular debris degradation (lysosomic and autophagic processes), which allows their aggregation on the retina ${ }^{51}$ In addition, RPE cells are physiologically exposed to continuous oxidative stress, so they have a rapid turnover. The inflammatory response, together with the immune system, reacts to accumulation of waste material, creating chronic local inflammation that represents a nucleating site for the deposition of extracellular elements. ${ }^{52}$

The new therapeutic approach aims to stop disease progression, selectively blocking or slowing down the accumulation of the singular drusen components (Tables 3 and 4).

Several studies have shown a correlation between AMD drusen and $\mathrm{AD}$ plaques. Both contain amyloid- $\beta$ $(A \beta)$, in strong association with activated complement components. $^{53-55} \mathrm{~A} \beta$ is thought to be an activator of the complement system and could be a potential target for new therapies. ${ }^{51}$ Humanized monoclonal antibodies directed against $A \beta$ have been tested in mouse models, demonstrating that systemic immunotherapy reduces the accumulation of amyloid and complement components (C3) in the retina, improves functional response, and obtains structural preservation of RPE cells. ${ }^{56-58}$ Two different humanized monoclonal antibodies are now under evaluation in clinical trials: RN6G (Pfizer, New York, NY, USA) and GSK933776 (GlaxoSmithKline, Verona, Italy).

Another drug called glatiramer acetate has been shown to be able to reduce $\mathrm{AD}$ plaques in mice. ${ }^{59}$ The same effect has been demonstrated on drusen in mouse models of AMD. ${ }^{60,61}$ Clinical trials on glatiramer acetate and dry AMD are ongoing.

\section{Reduce or eliminate inflammation}

Many complement components and inflammatory molecules are found in drusen. Several genetic studies show a link between complement-related proteins and AMD risk. ${ }^{62}$ 
Table 3 Summary of current trials on dry AMD therapy based on drusen components

\begin{tabular}{|c|c|c|c|}
\hline Type of drug & Name of the drug & Way of administration & Reference \\
\hline \multirow{4}{*}{$\begin{array}{l}\text { Anti- } \beta \text {-amyloid } \\
\text { antibodies }\end{array}$} & RN6G & Intravenous & ClinicalTrials.gov NCT0I57738I (suspended) \\
\hline & GSK933776 & Intravenous & ClinicalTrials.gov. NCT0I342926 (ongoing) \\
\hline & Glatiramer acetate & Weekly injection & ClinicalTrials.gov. NCT00466076 (status unknown) \\
\hline & & Subcutaneous & ClinicalTrials.gov. NCT0054I333 (suspended) \\
\hline \multirow[t]{4}{*}{ Anti-C5 antibodies } & LFG316 & Intravitreal & ClinicalTrials.gov. NCT0I255462 (completed, no results available) \\
\hline & & Intravitreal & ClinicalTrials.gov. NCTOI 527500 (recruiting patients) \\
\hline & ARCI 905 & Intravitreal & ClinicalTrials.gov. NCT00950638 (completed, no results available) \\
\hline & Eculizumab & Intravenous & Results found in "The COMPLETE study" (Yehoshua et al) ${ }^{86}$ \\
\hline Anti-factor D antibody & Lampalizumab & Intravitreal & Results found in "The MAHALO study" (Mones) ${ }^{64}$ \\
\hline \multirow[t]{4}{*}{ Anti-inflammatory agents } & Fluocinolone acetonide & Intravitreal & ClinicalTrials.gov. NCT006953I8 (ongoing) \\
\hline & Rapamycin & Intravitreal & ClinicalTrials.gov. NCTOI675947 (completed, no results available) \\
\hline & & Subconjuntival & Results in "The SIRGA study" (Wong et al) $)^{65}$ \\
\hline & & Intravitreal & $\begin{array}{l}\text { ClinicalTrials.gov. NCT0I } 445548 \text { (completed, results } \\
\text { available online) }\end{array}$ \\
\hline Lipids & Statins & Oral & Cochrane review (Gehlbach et al) $)^{72}$ \\
\hline
\end{tabular}

Abbreviations: AMD, age-related macular degeneration; COMPLETE, COMPLement Inhibition with Eculizumab for the Treatment of NonExudative Age-Related Macular Degeneration; GA, geographic atrophy; SIRGA, Sirolimus in the Treatment of Bilateral GA Associated With AMD.

The alternative complement pathway is thought to be the most involved. ${ }^{21,63}$ Modulating the complement factors may reduce their excessive activation and the subsequent immunemediated damage to the RPE.

Good results have been shown in the context of intravitreal administration of an antibody against complement factor D, called lampalizumab (FCFD4514S; Genentech Inc, Roche, San Francisco, CA, USA). A phase 2 study has been recently completed, showing good results: $20.4 \%$ reduction in GA progression at month 6 and month 18, with an acceptable safety profile. ${ }^{64}$

Anti-complement component 5 (C5) antibodies are also under evaluation for intravitreal administration: LFG316 (Novartis, Basel, Switzerland), ARC1905 (Ophthotech, Princeton, NJ, USA), and eculizumab (Soliris ${ }^{\circledR}$; Alexion Pharmaceuticals, Cheshire, CT, USA). As drusen formation triggers chronic local inflammation, anti-inflammatory drugs represent another possible therapeutic strategy. Fluocinolone acetonide (Iluvien ${ }^{\mathrm{TM}}$; Alimera Sciences, Alpharetta, GA, USA) is a nonbioerodible polyamide tube containing corticosteroid with a broad anti-inflammatory target. An ongoing phase 2 study aims to evaluate intravitreal administration in GA (Fluocinolone Acetonide Intravitreal Inserts in Geographic Atrophy).
Some studies have also considered rapamycin, which is a macrolide with anti-inflammatory activity. Two studies, phase 1 and phase 2, have recently been completed, evaluating subconjunctival (Pilot Study of the Evaluation of Subconjunctival Sirolimus in the Treatment of Bilateral GA Associated With AMD, SIRGA) or intravitreal (Sirolimus for Advanced Age-Related Macular Degeneration, SIRGA2) administration of the drug, but the results show that it does not prevent GA progression. ${ }^{65}$ Conversely, it seems to be associated with detrimental effect on VA.

Many other drusen components could be potential targets for dry AMD therapy, but studies are still at a preclinical stage ${ }^{66}$ For example, microglia and macrophages, in order to modulate its recruitment to the site of injury, or mast cells, to prevent its degranulation. ${ }^{67,68}$ To date, our knowledge on the role of inflammation and immune system is fairly advanced. It remains still unclear if they are protectors or drivers of retinal degeneration. Maybe this lack of understanding can explain the great amount of immune therapy failure in AMD. More efforts are needed to better identify new therapeutic strategies based on specific and well-known targets. ${ }^{50}$

Lipids are also found in drusen and several studies demonstrate that lipids accumulate at the site of subsequent

Table 4 Summary of current and future targets of dry AMD therapy based on drusen components

\begin{tabular}{lll}
\hline Targets & Strategy & Reference \\
\hline Complement components & Prevention of activation/accumulation & Anderson et al ${ }^{21}$ \\
Proteins of acute phase response to inflammation & Modulation/inhibition & Modulation of recruitment to the site of injury \\
$\begin{array}{l}\text { Microglia and macrophages } \\
\text { Mast cells }\end{array}$ & Prevention of degranulation & Combadiere et al $^{67}$ \\
\hline
\end{tabular}

Abbreviation: AMD, age-related macular degeneration. 
formation of AMD deposits. This accumulation has a detrimental effect on RPE because the oxidative stress over time results in the formation of lipid peroxidation products that cannot be digested by lysosomes. ${ }^{69}$ Similar to atherosclerotic plaques, these accumulations may contribute to the adverse effects on RPE structure and function. ${ }^{70,71}$

To date, the role of lipid metabolism in AMD is poorly understood, but it is clear that lowering lipid accumulation in Bruch's membrane could be an efficient strategy to treat AMD in the first phases. In fact, some authors have evaluated statin efficacy in AMD. Unfortunately, the results are inconclusive, as reported in a recent Cochrane review. ${ }^{72}$

\section{Lower the accumulation of toxic by-products from visual cycle}

The aim is to slow down photoreceptor activity to reduce the accumulation of their toxic by-products, such as N-retinylidene-N-retinylethanolamine (A2-E) and lipofuscin, preventing death of RPE and photoreceptor cells. These drugs are still in phase 2 studies (fenretinide and ACU-4429) or preclinical stage (ALK-001) but represent an exciting possibility for treating AMD.

\section{Fenretinide}

Fenretinide (RT-101; ReVision Therapeutics, San Diego, CA, USA) decreases the blood pool of vitamin A, which is the base for A2-E biosynthesis. Fenretinide has shown antiangiogenic and anti-inflammatory properties too..$^{73}$

\section{ACU-4429}

ACU-4429 (Acucela, Inc, Seattle, WA, USA), in experimental models, decreases the accumulation of A2-E, modulating the enzyme RPE65 that converts trans-retinol to cis-retinol within the RPE and slowing down the visual cycle.

\section{ALK-00 I}

ALK-001 (Alkeus Pharmaceuticals, Boston, MA, USA) is a modified vitamin $\mathrm{A}$, which avoids the dimerization of vitamin A molecules to form A2-E and lipofuscin. ${ }^{49}$

\section{Reduce or eliminate retinal oxidative stress}

Neuroprotective drugs preserve macular function by preventing apoptosis of viable RPE cells and photoreceptors. Several drugs are under investigation, such as ciliary neurotrophic factor (CNTF), brimonidine tartrate, and tandospirone, but none of them has shown a significant efficacy at the moment.

\section{CNTF}

CNTF was developed as an intravitreal sustained-release device for retinitis pigmentosa, and it is now studied for treating AMD. In animal models, it was shown to inhibit photoreceptor cell apoptosis. In a phase 2 clinical trial (NT501, Renexus, Cumberland, RI, USA) in patients with GA, its effect in preserving VA has been demonstrated, but without any significant difference from the sham group. No benefit in terms of the progression of lesion was found. ${ }^{74}$

\section{Brimonidine tartrate}

This alpha-2 adrenergic receptor agonist is able to stimulate the production of neurotrophic factors and protect photoreceptor cells in animal models of retinal degeneration. ${ }^{75}$ It is now being evaluated in a phase 2 clinical trial as an intravitreal implant (posterior-segment drug delivery system, Allergan, Irvine, CA, USA).

\section{Tandospirone}

Tandospirone (AL-8309B; Alcon, Fort Worth, TX, USA) is a selective serotonin $1 \mathrm{~A}$ agonist protecting the retina from photooxidative stress. It has been used as a topical ophthalmic solution in GA, in a phase 3 trial, but discontinued in 2012 owing to its lack of efficacy. ${ }^{76}$

\section{Improve choroidal perfusion}

The choroid provides oxygen and nourishment to the outer retinal layers. Impairment in choroidal blood flow is one of the supposed pathogenetic mechanisms of AMD. Several drugs have been tested, but none has demonstrated efficacy: eg, trimetazidine, MC-1101, sildenafil, and moxaverine.

\section{Trimetazidine}

Trimetazidine is currently used to treat angina. In a recent study, it failed in slowing down the progression of GA. ${ }^{77}$

\section{MC- I IO I}

MC-1101 (MacuCLEAR, Inc, Plano, TX, USA) has antiinflammatory and antioxidative properties and it is supposed to increase choroidal blood flow. A phase 1 study highlighted that patients with AMD using MC-1101 had a modest increase in choroidal blood flow within 2 hours postdosing.

\section{Moxaverine}

Moxaverine ${ }^{78}$ is a phosphodiesterase inhibitor that increases choroidal mean flow velocity in the ophthalmic artery and in posterior ciliary arteries. Its role in dry AMD needs to be investigated. 


\section{Sildenafil}

Sildenafil is effective on retinal vessels, ${ }^{79}$ but no improvement in choroidal blood flow has been found.

\section{Replace, repair, or regenerate lost RPE cells and photoreceptors}

Due to its high metabolic activity, the RPE represents an ideal tissue for transplantation in AMD.

Several strategies, either allogeneic or autologous, have been tried to transplant RPE cells in degenerated areas, without great success due to ${ }^{80}$ graft rejection, poor viability of cells, and complex attachment to the Bruch's membrane.

New promising approaches employ embryonic stem cells isolated from human blastocysts. In vitro, they are pluripotent and so are able to differentiate in RPE cells if adequately stimulated. Several surgical approaches to transplant these cells have been used in ongoing clinical trials. ${ }^{81}$

But what if the photoreceptor cells are dead? A new frontier is now represented by the simultaneous transplantation of photoreceptors and RPE cells. ${ }^{81}$ Rod precursors, obtained from both developing retina and human embryonic stem cells, have been used in animal models. Transplantation of rod precursors has shown improved vision in mice that lack rod function. ${ }^{82,83}$

\section{Gene therapy}

Genomic findings of the past have identified many genes associated with AMD, such as $C F H$ or age-related maculopathy susceptibility 2 (ARMS $\left.2^{81}\right)$. To date, genetics has helped us in the risk prediction of disease development/ progression, but our knowledge is still incomplete. Future developments could lead us to use genetic analysis to assess patient response to therapy, thus helping us to choose the most efficient treatment option. ${ }^{84,85}$

\section{Conclusion}

In general terms, therapeutic approaches to GA should be aimed at reducing or blocking the noxious stimuli, protecting the remaining cells, and further repairing, replacing, or regenerating the damaged ones. Current and continuing advances in understanding the molecular pathogenesis of early AMD and GA are identifying new relevant therapeutic targets, coupled with the advances in detecting and measuring disease progression. Breakthroughs in developing therapies that block and/or reverse early AMD and GA are expected. While there are many challenges and unmet needs in understanding and treating early and atrophic AMD, this is an exciting time to be working in this area.

\section{Disclosure}

The authors report no conflicts of interest in this work.

\section{References}

1. Allikmets R, Shroyer NF, Singh N, et al. Mutation of the stargardt disease gene (ABCR) in age-related macular degeneration. Science. 1997;277(5333):1805-1807.

2. Klein R, Klein EKB, Jensen SC, Meuer SM. The five-year incidence and progression of age-related maulopathy: the Beaver Dam Eye Study. Ophthalmology. 1997;104(1):7-21.

3. Zarbin MA. Current concepts in the pathogenesis of age-related macular degeneration. Arch Ophthalmol. 2004;122(4):598-614.

4. Donoso LA, Kim D, Frost A, Callahan A, Hageman G. The role of inflammation in the pathogenesis of age-related macular degeneration. Surv Ophthalmol. 2006;51(2):137-152.

5. Penfold PL, Madigan MC, Gillies MC, Provis JM. Immunological and aetiological aspects of macular degeneration. Progr Retin Eye Res. 2001;20(3):385-414.

6. Clemons TE, Milton RC, Klein R, Seddon JM, Ferris FL 3rd; AgeRelated Eye Disease Study Research Group. Risk factors for the incidence of Advanced age-related macular degeneration in the age-related eye disease study (AREDS) AREDS report no. 19. Ophthalmology. 2005;112(4):533-539.

7. Blumenkranz MS, Russell SR, Robey MG, Kott-Blumenkranz R, Penneys N. Risk factors in age-related maculopathy complicated by choroidal neovascularization. Ophthalmology. 1986;93(5):552-558.

8. Evans JR. Risk factors for age-related macular degeneration. Prog Retin Eye Res. 2001;20(2):227-253.

9. The Eye Disease Case-Control Study Group. Risk factors for neovascular age-related macular degeneration. Arch Ophthalmol. 1992;110(12):1701-1708.

10. Loffler KU, Lee WR. Basal linear deposit in the human macula. Graefes Arch Clin Exp Ophthalmol. 1986;224(6):493-501.

11. Curcio CA, Millican CL. Basal linear deposit and large drusen are specific for early age-related maculopathy. Arch Ophthalmol. 1999;117(3):329-339.

12. Sarks SH. Council Lecture. Drusen and their relationship to senile macular degeneration. Aust J Ophthalmol. 1980;8(2):117-130.

13. Munch IC, Sander B, Kessel L, et al. Heredity of small hard drusen in twins aged $20-46$ years. Invest Ophthalmol Vis Sci. 2007;48(2):833-838

14. Mullins RF, Russell SR, Anderson DH, Hageman GS. Drusen associated with aging and age-related macular degeneration contain proteins common to extracellular deposits associated with atherosclerosis, elastosis, amyloidosis, and dense deposit disease. FASEB J. 2000;14(7):835-846.

15. Nowak JZ. Age-related macular degeneration (AMD): pathogenesis and therapy. Pharmacol Rep. 2006;58(3):353-363.

16. Klein R, Klein BE, Tomany SC, Meuer SM, Huang GH. Ten-year incidence and progression of age-related maculopathy: the Beaver Dam eye study. Ophthalmology. 2002;109(10):1767-1779.

17. Malek G, Li CM, Guidry C, Medeiros NE, Curcio CA. Apolipoprotein B in cholesterol containing drusen and basal deposits of human eyes with age-related maculopathy. Am J Pathol. 2003;162(2):413-425.

18. Haimovici R, Gantz DL, Rumelt S, Freddo TF, Small DM. The lipid composition of drusen, Bruch's membrane, and sclera by hot stage polarizing light microscopy. Invest Ophthalmol Vis Sci. 2001;42(7):1592-1599.

19. Russell SR, Mullins RF, Schneider BL, Hageman GS. Location, substructure, and composition of basal laminar drusen compared with drusen associated with aging and age-related macular degeneration. Am J Ophthalmol. 2000;129(2):205-214.

20. Sivaprasad S, Chong NV. The complement system and age related macular degeneration. Eye (Lond). 2006;20(8):867-872.

21. Anderson DH, Radeke MJ, Gallo NB, et al. The pivotal role of the complement system in aging and age-related macular degeneration: hypothesis re-visited. Prog Retin Eye Res. 2010;29(2):95-112. 
22. Sarks SH. Ageing and degeneration in the macular region: a clinicopathological study. Br J Ophthalmol. 1976;60(5):324-341.

23. Schmitz-Valckenberg S, Bindewald-Wittich A, Dolar-Szczasny J, et al; Fundus Autofluorescence in Age-Related Macular Degeneration Study Group. Correlation between the area of increased autofluorescence surrounding geographic atrophy and disease progression in patients with AMD. Invest Ophthalmol Vis Sci. 2006;47(6):2648-2654.

24. Sunness JS, Gonzalez-Baron J, Bressler NM, Hawkins B, Applegate CA. The development of choroidal neovascularisation in eyes with the geographic atrophy form of age-related macular degeneration. $O p h-$ thalmology. 1999;106(5):910-919.

25. Schatz H, McDonald HR. Atrophic macular degeneration. Rate of spread of geographic atrophy and visual loss. Ophthalmology. 1989;96(10):1541-1551.

26. Holz FG, Bellmann C, Margaritidis M, Schütt F, Otto TP, Völcker HE Patterns of increased in vivo fundus autofluorescence in the junctional zone of geographic atrophy of the retinal pigment epithelium associated with age-related macular degeneration. Graefes Arch Clin Exp Ophthalmol. 1999;237(2):145-152.

27. Velilla S, García-Medina JJ, García-Layana A, et al. Smoking and age-related macular degeneration: review and update. $J$ Ophthalmol. 2013;2013:895147.

28. Chong EW, Kreis AJ, Wong TY, Simpson JA, Guymer RH. Alcohol consumption and the risk of age-related macular degeneration: a systematic review and meta-analysis. Am J Ophthalmol. 2008;145(4):707-715.

29. Peeters A, Magliano DJ, Stevens J, Duncan BB, Klein R, Wong TY. Changes in abdominal obesity and age-related macular degeneration: the atherosclerosis risk in communities study. Arch Ophthalmol. 2008;126(11):1554-1560.

30. Merle B, Delyfer MN, Korobelnik JF, et al. Dietary omega-3 fatty acids and the risk for age-related maculopathy: the Alienor Study. Invest Ophthalmol Vis Sci. 2011;52(8):6004-6011.

31. Cook HL, Patel PJ, Tufail A. Age-related macular degeneration: diagnosis and management. Br Med Bull. 2008;85:127-149.

32. Hooper P, Jutai JW, Strong G, Russell-Minda E. Age-related macular degeneration and low-vision rehabilitation: a systematic review. Can J Ophthalmol. 2008;43(2):180-187.

33. Age-Related Eye Disease Study Research Group. A randomized, placebo-controlled, clinical trial of high-dose supplementation with vitamins $\mathrm{C}$ and $\mathrm{E}$, beta carotene, and zinc for age-related macular degeneration and vision loss: AREDS report no. 8. Arch Ophthalmol. 2001;119(10):1417-1436. [Erratum in Arch Ophthalmol. 2008 Sep;126(9):1251].

34. Age-Related Eye Disease Study 2 Research Group. Lutein + zeaxanthin and omega- 3 fatty acids for age-related macular degeneration: the agerelated eye disease study 2 (AREDS2) randomized clinical trial. JAMA. 2013;309(19):2005-2015.

35. Cano M, Thimmalappula R, Fujihara M, et al. Cigarette smoking, oxidative stress, the anti-oxidant response through Nrf2 signaling, and age-related macular degeneration. Vision Res. 2010;50(7):652-664.

36. Klevering BJ. Zinc and the complement system. Antioxidants and AMD: into the mechanisms. Paper presented at: The Annual Meeting of the Association for Research in Vision and Ophthalmology; May; 2013; Seattle, Washington.

37. Vishwanathan R, Chung M, Johnson EJ. A systematic review on zinc for the prevention and treatment of age-related macular degeneration. Invest Ophthalmol Vis Sci. 2013;54(6):3985-3998.

38. Sin HP, Liu DT, Lam DS. Lifestyle modification, nutritional and vitamins supplements for age-related macular degeneration. Acta Ophthalmol. 2013;91(1):6-11.

39. Chong EWT, Wong TY, Kreis AJ, Simpson JA, Guymer RH. Dietary antioxidants and primary prevention of age related macular degeneration: systematic review and meta-analysis. BMJ. 2007;335(7623):755.

40. Chong EW, Kreis AJ, Wong TY, Simpson JA, Guymer RH. Dietary omega-3 fatty acid and fish intake in the primary prevention of agerelated macular degeneration: a systematic review and meta-analysis. Arch Ophthalmol. 2008;126(6):826-833.
41. Maccarone R, Di Marco S, Bisti S. Saffron supplement maintains morphology and function after exposure to damaging light in mammalian retina. Invest Ophthalmol Vis Sci. 2008;49(3):1254-1261.

42. Falsini B, Piccardi M, Minnella A, et al. Influence of saffron supplementation on retinal flicker sensitivity in early age-related macular degeneration. Invest Ophthalmol Vis Sci. 2010;51(12):6118-6124.

43. Mandal MN, Patlolla JM, Zheng L, et al. Curcumin protects retinal cells from light-and oxidant stress-induced cell death. Free Radic Biol Med. 2009;46(5):672-679.

44. Chang YC, Chang WC, Hung KH, et al. The generation of induced pluripotent stem cells for macular degeneration as a drug screening platform: identification of curcumin as a protective agent for retinal pigment epithelial cells against oxidative stress. Front Aging Neurosci. 2014;6:191.

45. Christen WG, Glynn RJ, Chew EY, Albert CM, Manson JE. Folic acid, pyridoxine, and cyanocobalamin combination treatment and age-related macular degeneration in women: the women's antioxidant and folic acid cardiovascular study. Arch Intern Med. 2009;169(4):335-341.

46. King RE, Kent KD, Bomser JA. Resveratrol reduces oxidation and proliferation of human retinal pigment epithelial cells via extracellular signal-regulated kinase inhibition. Chem Biol Interact. 2005;151(2):143-149.

47. Nagineni CN, Raju R, Nagineni KK, et al. Resveratrol suppresses expression of VEGF by human retinal pigment epithelial cells: potential nutraceutical for age-related macular degeneration. Aging Dis. 2014;5(2):88-100.

48. Klein ML, Ferris FL 3rd, Armstrong J, et al; AREDS Research Group. Retinal precursors and the development of geographic atrophy in age-related macular degeneration. Ophthalmology. 2008;115(6):1026-1031.

49. Holz FG, Strauss EC, Schmitz-Valckenberg S, van Lookeren Campagne M. Geographic atrophy: clinical features and potential therapeutic approaches. Ophthalmology. 2014;121(5):1079-1091.

50. Ambati J, Atkinson JP, Gelfand BD. Immunology of age-related macular degeneration. Nat Rev Immunol. 2013;13:438-451.

51. Wang J, Ohno-Matsui K, Yoshida T, et al. Amyloid-beta up-regulates complement factor $\mathrm{B}$ in retinal pigment epithelial cells through cytokines released from recruited macrophages/microglia: another mechanism of complement activation in age-related macular degeneration. $J$ Cell Physiol. 2009;220(1):119-128.

52. Anderson DH, Mullins RF, Hageman GS, Johnson LV. A role for local inflammation in the formation of drusen in the aging eye. $A m J$ Ophthalmol. 2002;134(3):411-431.

53. Loeffler K, Edward D, Tso M. Immunoreactivity against tau, amyloid precursor protein, and beta-amyloid in the human retina. Invest Ophthalmol Vis Sci. 1995;36(1):24-31.

54. Johnson LV, Leitner WP, Rivest AJ, Staples MK, Radeke MJ, Anderson DH. The Alzheimer's A beta-peptide is deposited at sites of complement activation in pathologic deposits associated with aging and age-related macular degeneration. Proc Natl Acad Sci U S A. 2002;99(18):11830-11835.

55. Ohno-Matsui K. Parallel findings in age-related macular degeneration and Alzheimer's disease. Prog Retin Eye Res. 2011;30(4):217-238.

56. Ding JD, Lin J, Mace BE, Herrmann R, Sullivan P, Bowes Rickman C. Targeting age-related macular degeneration with Alzheimer's disease based immunotherapies: anti-amyloid-beta antibody attenuates pathologies in an age-related macular degeneration mouse model. Vision Res. 2008;48(3):339-345.

57. Ding JD, Johnson LV, Herrmann R, et al. Anti-amyloid therapy protects against retinal pigmented epithelium damage and vision loss in a model of age-related macular degeneration. Proc Natl Acad Sci U S A. 2011;108(28):E279-E287.

58. Catchpole I, Germaschewski V, Hoh Kam J, et al. Systemic administration of Abeta $\mathrm{mAb}$ reduces retinal deposition of Abeta and activated complement $\mathrm{C} 3$ in age-related macular degeneration mouse model. PLoS One. 2013;8(6):e65518.

59. Butovsky O, Koronyo-Hamaoui M, Kunis G, et al. Glatiramer acetate fights against Alzheimer's disease by inducing dendritic-like microglia expressing insulin-like growth factor 1. Proc Natl Acad Sci USA. 2006;103(31): 11784-11789. 
60. Landa G, Butovsky O, Shoshani J, Schwartz M, Pollack A. Weekly vaccination with Copaxone (glatiramer acetate) as a potential therapy for dry age-related macular degeneration. Curr Eye Res. 2008;33(11):1011-1013.

61. Landa G, Rosen RB, Patel A, et al. Qualitative spectral OCT/SLO analysis of drusen change in dry age-related macular degeneration patients treated with Copaxone. J Ocul Pharmacol Ther. 2011;27(1):77-82.

62. Ratnapriya R, Chew EY. Age-related macular degeneration-clinical review and genetics update. Clin Genet. 2013;84(2):160-166.

63. Tuo J, Grob S, Zhang K, Chan CC. Genetics of immunological and inflammatory components in age-related macular degeneration. Ocul Immunol Inflamm. 2012;20(1):27-36.

64. Mones J. The MAHALO Phase II Results. Lampalizumab (Anti-factor D) in Patients with Geographic Atrophy. South San Francisco, CA: Genentech, Inc; 2014.

65. Wong WT, Dresner S, Forooghian F, et al. Treatment of geographic atrophy with subconjunctival sirolimus: results of a phase I/II clinical trial. Invest Ophthalmol Vis Sci. 2013;54(4):2941-2950.

66. Bowes Rickman C, Farsiu S, Toth CA, Klingeborn M. Dry age-related macular degeneration: mechanisms, therapeutic targets, and imaging. Invest Ophthalmol Vis Sci. 2013;54(14):ORSF68-ORSF80.

67. Combadière C, Feumi C, Raoul W, et al. CX3CR1-dependent subretinal microglia cell accumulation is associated with cardinal features of agerelated macular degeneration. J Clin Invest. 2007;117:2920-2928.

68. Lutty GA, Bhutto I, Seddon J, McLeod D. Mast cell degranulation in AMD choroid. Invest Ophtalmol Vis Sci. 2013;54. [ARVO E-Abstract 3051].

69. Ebrahimi KB, Handa JT. Lipids, lipoproteins, and age-related macular degeneration. J Lipids. 2011;2011:802059.

70. Tabas I, Williams KJ, Borén J. Subendothelial lipoprotein retention as the initiating process in atherosclerosis: update and therapeutic implications. Circulation. 2007;116(16):1832-1844.

71. Curcio CA, Johnson M, Huang JD, Rudolf M. Apolipoprotein B-containing lipoproteins in retinal aging and age-related macular degeneration. J Lipid Res. 2010;51(3):451-467.

72. Gehlbach P, Li T, Hatef E. Statins for age-related macular degeneration. Cochrane Database Syst Rev. 2012;3:CD006927.

73. Mata NL, Lichter JB, Vogel R, Han Y, Bui TV, Singerman LJ. Investigation of oral fenretinide for treatment of geographic atrophy in age-related macular degeneration. Retina. 2013;33(3):498-507.

74. Zhang K, Hopkins JJ, Heier JS, et al. Ciliary neurotrophic factor delivered by encapsulated cell intraocular implants for treatment of geographic atrophy in age-related macular degeneration. Proc Natl Acad Sci U S A. 2011;108(15):6241-6245.
75. Lai RK, Chun T, Hasson D, Lee S, Mehrbod F, Wheeler L. Alpha-2 adrenoceptor agonist protects retinal function after acute retinal ischemic injury in the rat. Vis Neurosci. 2002;19(2):175-185.

76. Collier RJ, Wang Y, Smith SS, et al. Complement deposition and microglial activation in the outer retina in light-induced retinopathy: inhibition by a 5-HT1A agonist. Invest Ophthalmol Vis Sci. 2011;52(11):8108-8116.

77. Cohen SY, Bourgeois H, Corbe C, et al. Randomized clinical trial France DMLA2: effect of trimetazidine on exudative and nonexudative age-related macular degeneration. Retina. 2012;32(4):834-843.

78. Pemp B, Garhofer G, Lasta M, Schmidl D, Wolzt M, Schmetterer L. The effects of moxaverine on ocular blood flow in patients with agerelated macular degeneration or primary open angle glaucoma and in healthy control subjects. Acta Ophthalmol. 2012;90(2):139-145.

79. Harris A, Kagemann L, Ehrlich R, Ehrlich Y, López CR, Purvin VA. The effect of sildenafil on ocular blood flow. Br J Opthalmol. 2008; 92(4):469-473

80. Pan CK, Heilweil G, Lanza R, Schwartz SD. Embryonic stem cells as a treatment for macular degeneration. Expert Opin Biol Ther. 2013;13(8):1125-1133.

81. Carr AJ, Smart MJ, Ramsden CM, Powner MB, Da Cruz L, Coffey PJ. Development of human embryonic stem cell therapies for age-related macular degeneration. Trends Neurosci. 2013;36(7):385-395.

82. Pearson RA, Barber AC, Rizzi M, et al. Restoration of vision after transplantation of photoreceptors. Nature. 2012;485:99-103.

83. Singh MS, Charbel Issa P, Butler R, et al. Reversal of end-stage retinal degeneration and restoration of visual function by photoreceptor transplantation. Proc Natl Acad Sci U S A. 2013;110(3):1101-1106.

84. Priya RR, Chew EY, Swaroop A. Genetic studies of age-related macular degeneration: lessons, challenges, and opportunities for disease management. Ophthalmology. 2012;119(12):2526-2536.

85. Gorin MB. Genetic insights into age-related macular degeneration: controversies addressing risk, causality, and therapeutics. Mol Aspects Med. 2012;33(4):467-486.

86. Yehoshua Z, de Amorim Garcia Filho CA, Nunes RP, et al. Systemic complement inhibition with eculizumab for geographic atrophy in agerelated macular degeneration: the COMPLETE study. Ophthalmology. 2014;121(3):693-701.
Clinical Ophthalmology

\section{Publish your work in this journal}

Clinical Ophthalmology is an international, peer-reviewed journal covering all subspecialties within ophthalmology. Key topics include: Optometry; Visual science; Pharmacology and drug therapy in eye diseases; Basic Sciences; Primary and Secondary eye care; Patient Safety and Quality of Care Improvements. This journal is indexed on Submit your manuscript here: http://www.dovepress.com/clinical-ophthalmology-journal

\section{Dovepress}

PubMed Central and CAS, and is the official journal of The Society of Clinical Ophthalmology (SCO). The manuscript management system is completely online and includes a very quick and fair peer-review system, which is all easy to use. Visit http://www.dovepress.com/ testimonials.php to read real quotes from published authors. 